\title{
La matrícula de mar y el banco sahariano ${ }^{1}$
}

\author{
JuAn Manuel Santana \\ The Register of Seamen and the Saharan Bank
}

\begin{abstract}
RESUMEN:
La Matrícula de Mar fue una medida que se implantó en la Corona española, cuyo objetivo principal era disponer de efectivos militares para la Marina de Guerra.

La organización de la Matrícula responde principalmente a motivos militares: el fomento de la pesca no tuvo más que un papel subsidiario en este fenómeno. Sólo interesaba en la medida que su número pudiera contribuir a incrementar y preparar la cifra de marineros aptos para la Armada, aunque de forma secundaria se decía que trataba de fomentar la pesca para reducir la dependencia de las importaciones de bacalao de países del norte de Europa.
\end{abstract}

Este sistema de reclutamiento se intentó llevar a la práctica de forma parcial en los años 1717, 1726, 1728 y 1737, mediante una serie de disposiciones. Sin embargo, a pesar de estos precedentes, la primera vez que la Matrícula de Mar fue implantada de

modo eficaz fue a partir de 1751-1754.

En Canarias la Matrícula no se aplicó hasta 1804, que aparecerá vinculada a la de Indias. El 6 de julio de 1804 se estableció en Tenerife una Subdelegación de Matrícula, por cuya disposición se registró a toda la gente de mar.

\author{
ABSTRACT: \\ The Register of Seamen was a measure \\ taken in the Kingdom of Spain to recruit \\ soldiers for the navy.
}

The creation of the Register of Seamen answered to military motivation, fostering the fishing activity acquiring a secondary role in this process. The only interest was to bring fishermen to the navy. This situation, as well, helped decrease the dependency on the cod industry of Northern Europe.

This system was put into practice partially in 1717, 1726, 1728, and 1737, under a number of regulations. In spite of these initial efforts, it was not until 1751 and 1754 that the Register of Seamen was implemented.

In the Canary Islands, the Register of Seamen was not at work until 1804. Until then, it had only been functional in Mainland Spain and Spanish America. On July 6th, 1804, the Spanish Government set up in the island of Tenerife a Subcommittee of the Register of Seamen which regulated the recruitment of fishermen.

Recibido: 11-02-2010 Aceptado: 08-07-2010

\footnotetext{
* Universidad de las Palmas de Gran Canaria. Departamento de Ciencias Históricas. Pza de la Constitución s/n 38003. Las Palmas de Gran Canaria juansantana @ dch.ulpgc.es

1 Este artículo se enmarca en un proyecto de I+D+i financiado por el Ministerio de Educación y Ciencia con el código HUM2007-61834/HIST.
} 
PALABRAS CLAVE:

Matrícula de Mar, Pescadores, Islas Atlánticas, Banco Pesquero Sahariano, Historia Marítima.
KEYWORDS:

Registration of Seamen, Fishermen, Atlantic Islands, Saharan Fishing Bank, Maritime History.

\section{PLANTEAMIENTO GENERAL}

El tema de esta investigación, la creación de la Matrícula de Mar, fue un asunto generado por una política militar interesada en la recuperación de la Marina de guerra hispana tras la pérdida de hegemonía desde el siglo XVI. En diversos momentos se pensó que la forma óptima para superar ese bache era la creación de una Matrícula de Mar, que consistía en el registro de todas las personas que se dedicasen a actividades marítimas, entre las que destacaban los pescadores, que a partir de ese momento tendrían que estar listos para formar parte de la Real Armada a cambio de ciertas contrapartidas, como la de poder seguir manteniendo su oficio.

Las fuentes para conocer este tema las hemos encontrado diseminadas en diversos archivos peninsulares y alguno canario, aunque llama la atención la poca documentación generada en las islas al respecto. Si bien es cierto que los Amigos del País trataron en alguna de sus sesiones esta problemática, no lo hicieron con profusión. Hallamos varias referencias en los extractos de sus actas ,transcritas por uno de sus miembros destacados, Viera y Clavijo.

La mayor parte de la información se halla en el Archivo General de Marina Don Álvaro de Bazán (A.G.M.A.B.), situado en la localidad del El Viso del Marqués. Hay documentación abundante sólo a partir de 1784, por haber sido segregada a partir de esa fecha, sin razón objetiva aparente, de la sección Secretaría de Marina del Archivo General de Simancas. En este archivo hemos consultado sobre todo la sección Matrículas en Generalidades y en Asuntos Particulares, donde hay referencias a la Matrícula del Mar en Canarias.

En el Archivo del Museo Naval (A.M.N.) en Madrid contamos con un manuscrito que toca el tema de la conservación de pescados en Canarias y sus deficiencias. En él se recogen también datos de interés sobre la matrícula del mar en Canarias, además de una copia de la descripción de Canarias que hizo José Varela y Ulloa, donde también hace referencias sobre el particular.

En el Archivo General de Simancas (A.G.S.) en la Sección Secretaría de Marina, sobre la Matrícula de Mar se conserva un documento, el legajo 276, que no es exclusivo de Canarias, sino un reglamento general con jurisdicción en toda la Corona.

En Canarias solamente hemos encontrado tratado este tema de forma colateral en algún acta del Cabildo de Tenerife, en el Archivo Municipal de La Laguna (A.M.L.L.) y en el diario del regidor de Gran Canaria Isidoro Romero y Cevallos. 
También hemos recurrido a la Novísima Recopilación de las leyes de España que en sus libros VI, título VII, y libro VII título XXX, recoge diversas normativas sobre el asunto.

Los estudios de la Matrícula de Mar, primeramente, estuvieron vinculados a la Historia Militar; de hecho, en ciertos aspectos, es una parcela de ésta. Pero, en general, en España, la Historia Marítima se ha abordado desde hace pocos años. En la década de los ochenta se inicia un tratamiento sistemático y científico con intentos de cuantificación de efectivos dedicados a la pesca. En este sentido, la Matrícula de Mar se presenta como una institución clave para conocer tanto los efectivos susceptibles de ser empleados en la política naval hispana como para dar una aproximación al conocimiento de las personas que se dedicaban al mundo de la pesca.

Desde el último cuarto del siglo XIX contamos con el trabajo de Javier de Salas, que en realidad hace una apología de la Matrícula de Mar, obligatoria para todos los españoles. Pero ya en el siglo XX debemos destacar dos autores que han escrito monografías muy completas dedicadas a este tema: Rolf Mühlmann ${ }^{2}$ y José Manuel Vázquez Lijó ${ }^{3}$. Debemos añadir los trabajos realizados por Roberto Fernández Díaz y Carlos Martínez Shaw, a los que poco después se unirá Marina Alfonso Mola en esfuerzos encaminados en la misma línea. Otros autores que han trabajado de forma monográfica sobre este tema son Ángel O'Dogherty, y, de forma conjunta, Olga López Miguel y Magda Mirabet Cucala. También hay otras publicaciones que hacen algunas alusiones a la Matrícula de Mar entre otras cuestiones relacionadas con la economía de zonas marítimas. La cuestión de la extensión de esta institución a las colonias americanas ha contado con algunas investigaciones centradas en una zona, como las de Adelaida Sagarra Gamazo para el Caribe colombiano y Amparo Moreno Gullón para el Caribe Mexicano. En nuestra opinión, la mejor visión global es la que aportan Marina Alfonso Mola y Carlos Martínez Shaw.

Sin embargo, la Matrícula en Canarias nunca había sido tratada con anterioridad, ni siquiera de forma tangencial; incluso en algún caso, se ha afirmado que corrió paralela a la del resto de España, y en otros se decía que nunca se llevó a cabo.

La Matrícula de Mar fue una medida que se implantó en toda la Corona española, cuyo objetivo principal era disponer de efectivos militares para la Marina de Guerra. Se trataba de una institución reguladora de la prestación de servicios en la Real Armada por parte de hombres cuyo oficio proporcionara los conocimientos de navegación necesarios para que todos los marineros disponibles estuviesen cen-

${ }^{2}$ Rolf MÜHLMANN, Die Reorganisation der Spanischen Kriegsmarine im 18, Colonia, Jahrhundert, 1975.

${ }^{3}$ José Manuel VÁZQUEZ LIJÓ, La matrícula de mar y sus repercusiones en la Galicia del siglo XVIII, Tesis Doctoral, Universidad de Santiago de Compostela, 2005. Existe un resumen de este trabajo publicado en Obradoiro de Historia Moderna, № 15, Santiago de Compostela, 2006, pp. 289-322. Este mismo autor tiene otro libro más reciente que trataremos más adelante. 
sados y listos para ser requeridos a filas; a cambio recibían una serie de privilegios. Los pescadores suponían un vivero de marinería para la Real Armada.

Esta norma tuvo poca influencia en la pesca en el Banco Sahariano en los siglos XVII y XVIII, porque a medida que avanzamos en el tiempo, fue quedando en manos de pescadores canarios y, en el Archipiélago la Matrícula no se aplicó hasta 1804. De todos modos, es un tema que tuvo incidencia a partir de las fechas en que entró en vigor.

La organización de la Matrícula responde principalmente a motivos militares: el fomento de la pesca no tuvo más que un papel subsidiario en este fenómeno. Sólo interesaba en la medida que su número pudiera contribuir a incrementar y preparar la cifra de marineros aptos para la Armada, aunque de forma secundaria se decía que trataba de fomentar la pesca para reducir la dependencia de las importaciones de bacalao de países del norte de Europa ${ }^{4}$.

El alistamiento y las periódicas revistas de inspección, con el constante conocimiento de los pescadores, fue el medio para alcanzar el fin propuesto. Los marineros debían acudir a campañas cada vez que fuesen llamados. Por ello, saber el paradero de cada uno de ellos pasó a ser una necesidad para asegurar el cumplimiento del servicio, lo que conllevaba un férreo control. Para facilitar la identificación, cada persona debía tener una cédula que lo acreditaba como tal, donde debía figurar su nombre, lugar de nacimiento, filiación, estado civil, edad, rasgos físicos y fecha de matriculación. Todo esto significaba un agravio para la gente de mar, contrapesado con ciertos privilegios que no eran suficientes para hacerla deseable.

La principal contrapartida era la exclusividad para dedicarse a la pesca. Una real orden en 1788 insiste en recalcar que ninguna persona que no estuviese matriculada podría dedicarse a la pesca, además, aquellos que pasasen de 50 años de edad y se hubiesen dedicado a la pesca toda su vida, debían ser matriculados en la clase de «inhábil», pero sus hijos tendrían que servir a la Marina de guerra con tres años de libertad del servicio. En 1802 se volvió a insistir en esta medida, al tiempo que se declaraba la exención de impuestos para los matriculados ${ }^{5}$.

Desde fines del siglo XVI, las autoridades españolas eran conscientes de la dificultad de reclutar las tripulaciones para los barcos de guerra. A partir de principios del siglo XVII se llevaron a cabo las primeras tentativas de establecer la Matrícu-

\footnotetext{
${ }^{4}$ La importación de pescado procedente de Europa se redujo ligeramente en la segunda mitad del siglo XVIII, aunque no se quebró del todo.Los ilustrados trataban de mejorar la balanza comercial con un aumento de la producción pesquera que permitiera reducir las importaciones masivas de pescado salado de los países nórdicos y, sobre todo, de Inglaterra, pero en el cómputo final de este proceso, veremos que los resultados fueron muy modestos y muy distantes de las expectativas creadas. Esto lo hemos abordado deforma monográfica en Juan Manuel SANTANA PÉREZ, «llustración canaria y pesca en el Litoral», en Alberto LÓPEZ BARGADOS y Jesús MARTÍNEZ MILÁN (ed.), Culturas del Litoral. Dinámicas fronterizas entre Canarias y la costa sahariano-mauritana, Barcelona, Bellaterra, 2010, pp. 67-90.

5 Novísima Recopilación de las Leyes de España. Libro VII, Título XXX, Ley XV, 3 de noviembre de 1788 y Ley XVII, 12 de agosto de 1802. Edición Facsímil, Madrid, Boletín Oficial del Estado, 1975, pp. 649-650.
} 
la en España. La primera que tuvo vigencia jurídica fue una real orden de 1607, que restringía su aplicación a Guipúzcoa, y otra posterior, la real cédula de 1625, cuyo ámbito de actuación alcanzaba a todos los reinos peninsulares, incluido Portugal, pero no incorporaba al Archipiélago Canario. En cualquier caso, ninguna de las dos pudo ser llevada a la práctica de forma efectiva como pretendían los legisladores ${ }^{6}$. En palabras de Javier de Salas, que fue el primero que trató este tema de la Matrícula de Mar en España, su efecto real quedó reducido a la mera confección de una estadística de la marinería del Reino ${ }^{7}$.

Con la Matrícula de Mar, los reformistas del siglo XVIII retomaron una idea ya planteada en tiempos de los Austrias, es decir, que sirvió de lejana inspiración a Patiño y a Ensenada para recomponer la Armada española. La recuperación de la marina de guerra constituyó uno de los puntos centrales en los proyectos del reformismo borbónico.

Este sistema de reclutamiento se intentó llevar a la práctica de forma parcial en los años 1717, 1726, 1728 y 1737, mediante una serie de disposiciones. El 28 de enero de 1717 se hizo el «Decreto de empadronamiento de la gente de mar»; el 29 de agosto de 1726 la «Real Orden de preeminencias concedidas a la gente matriculada», acompañada de una Instrucción» firmada por Patiño en la misma fecha; en 1728 las «Ordenanzas de su Majestad para el gobierno de la Armada Naval»; y el 18 de octubre de 1737, la «Real Cédula de privilegios e Instrucción del Almirante General Infante Don Felipe».

En esta última real cédula se establece de modo definitivo la Matrícula, decretando la exclusividad de los oficios de navegación y pesca a los matriculados y su sometimiento a la jurisdicción de la Marina, es decir, separándolos de la justicia ordinaria. El cuerpo de la Armada se dividía en tres Escuadras, con capitales establecidas en las ciudades de Cádiz, Ferrol y Cartagena. Aquí aparecen los privilegios de los que gozarían los matriculados: $1^{\circ}$ quedar exentos del sorteo de quintas para batallones de tierra, $2^{\circ}$ no tener que acoger tropas en sus casas en caso de necesidad, $3^{\circ}$ la medida anterior era extensiva a todos los matriculados, incluidos los solteros que vivieran en la casa de sus padres, $4^{\circ}$ no estar sujetos a la justicia ordinaria, $5^{\circ}$ con los mismos privilegios podrían inscribirse marineros católicos de otros países, $6^{\circ}$ únicamente los matriculados podrían participar en actividades pesqueras o del comercio marítimo, $7^{\circ}$ posibilidad de los matriculados de denunciar a los que practicasen actividades marítimas sin estar matriculados, $8^{\circ}$ debía ir un navío de guerra formado por los matriculados en las flotas, galeones, azogues o guardacostas hacia América, $9^{\circ}$ serían jubilados a partir de los 60 años, una vez que hubiesen servido durante 30 años, manteniendo sus

${ }^{6}$ Marina ALFONSO MOLA y Carlos MARTÍNEZ SHAW, «El reclutamiento de la gente de mar. Las matrículas de 1607 y 1625", en Antonio DE BÉTHENCOURT MASSIEU, Coloquio Internacional Canarias y el Atlántico 1580-1648, Las Palmas de Gran Canaria, Cabildo Insular de Gran Canaria, 2001, pp. 651693.

Javier DE SALAS, La Matrícula de Mar y examen de varios sistemas de reclutamiento marítimo, Madrid, Fortanet, 1879, p. 108. 
privilegios, $10^{\circ}$ esto último se aplicaría también a aquellos que cumpliesen 60 años de edad sin haber pasado 30 años como matriculados, 11ำ se crearían academias donde instruir en materia de navegación, especialmente dirigida a los nobles, y $12^{\circ}$ se les debía anticipar la paga a los que fuesen nombrados para servir en la Armada ${ }^{8}$.

Sin embargo, a pesar de estos precedentes, la primera vez que la Matrícula de Mar fue implantada de modo eficaz fue a partir de 1751-1754, respondiendo a la «Ordenanza para el régimen y fomento de la marinería matriculada», en el Título III del Tratado $X$ de las Ordenanzas para el gobierno de la Armada Naval, publicada el 1 de enero de 1751. Esta normativa permaneció vigente hasta la reorganización de la Matrícula de 1802. La Matrícula de Mar generó una ingente cantidad de documentos jurídicos y una abundante correspondencia entre los funcionarios que debían gestionarla y la Secretaría de Marina ${ }^{9}$. Dependía de la Secretaría de Marina, y en cada localidad, de un ministro de Marina que era un funcionario civil, hasta que a finales del siglo XVIII es sustituido por un militar.

En los planes de reclutamiento marino fueron tenidos en cuenta los ordenamientos navales de Francia y otros países marítimos, aunque hubo diferencias nítidas entre unos y otros países, especialmente destacables fueron el système des classes francés y el impressment como recurso de la Royal Navy británica ${ }^{10}$. El propio Campomanes apuntaba que la gran ventaja de la Armada inglesa se debía al desarrollo de su sector pesquero, que servía de escuela a la marinería para aprender los oficios militares marítimos en sus guerras ${ }^{11}$.

El plan del marqués de la Ensenada, quien había redactado la Ordenanza del Infante Almirante en su calidad de secretario del Almirantazgo, era el de reclutar 69.000 hombres, cifra que parece un tanto exagerada. Esa política para lograr una Armada resultaba desproporcionada para el potencial económico y demográfico de España, y tuvo repercusiones negativas, especialmente en la economía pesquera del norte de la Península Ibérica ${ }^{12}$ y, sin duda, en el resto de España. Los autores coetáneos ya habían calificado como negativas para el fomento de la pesca la normativa de reclutamiento marítimo.

8 A.G.S. Secretaría de Marina, Leg. 276.

9 Olga LÓPEZ MIGUEL y Magda MIRABET CUCALA, «La institucionalización de la Matrícula de Mar: textos normativos y consecuencias para la gente de mar y maestranza», en Carlos MARTíNEZ SHAW (Ed.), El derecho y el mar en la España moderna, Granada, Universidad de Granada-Centre D'Estudis d'Historia Moderna Pierre Vilar, 1995, los textos jurídicos en pp. 220-226.

10 José Manuel VÁZQUEZ LIJÓ, Las Matrículas de Mar en la España del siglo XVIII. Registro, inspección y evolución de las clases de marinería y maestranza, Madrid, Ministerio de Defensa, 2007.

11 Pedro RODRÍGUEZ CAMPOMANES, Reflexiones sobre el comercio español a Indias, Madrid, Instituto de Estudios Fiscales-Ministerio de Economía y Hacienda, 1988 p. 206.

12 Juan Gracias Cárcamo: «Las levas de marinería y la cofradía de pescadores de Bermeo en el siglo XVIII», en Aingeru ZABALA et al., Historia de la economía marítima del País Vasco, San Sebastián, Txertoa, 1983, p. 129. También contamos con un análisis de las repercusiones especialmente en los rasgos demográficos en San Vicente de la Barquera, Santander, Laredo y Castro Urdiales, en Miguel Ánge SÁNCHEZ GÓMEZ, "Las gentes de mar de las Cuatro Villas de la Costa de Cantabria en el siglo XVIII. Rasgos sociodemográficos", en Isidro DUBERT y Hortensio SOBRADO CORREA, El mar en los siglos modernos, T. I, Santiago de Compostela, Xunta de Galicia, 2009, pp. 169-181. 
Esta Matrícula era esencialmente militar y estaba siendo concebida como un mecanismo para la reestructuración de la marina de guerra, y respondía a la necesidad de contar con un censo de gente de mar y de maestranza. Su cometido era registrar a los hombres que se dedicasen a actividades marítimas: marinos, pescadores, carpinteros de ribera y calafates, con el fin de tener disponibles tripulaciones y equipos técnicos al ritmo de las necesidades de la Armada. Fue levantada por primera vez entre 1752 y 1756 y revisada periódicamente mediante inspecciones o revistas en cada Departamento.

En total se hicieron seis recuentos a lo largo del XVIII: 1752-1756, 1758$1765,1772-1773,1786,1796$ y 1799. No obstante, no existe uniformidad en los datos que ofrecen cada una de estas revistas ${ }^{13}$. Las revistas de inspección facilitaban el estado numérico de las matrículas. A partir de la inspección general se daban informes anuales ${ }^{14}$.

Se establecen tres Departamentos, que se subdividen en provincias y éstas a su vez en subdelegaciones. El Departamento de Cádiz engloba: Cádiz, Sevilla, Málaga, Sanlúcar, Algeciras, Ayamonte, Almería, y Motril; el Ferrol comprende: Pontevedra, La Coruña, El Ferrol, Vivero, Avilés, Ribadesella, y Santander; el Departamento levantino se divide en: Vera, Cartagena, Alicante, Valencia, Mallorca, Mahón, Tarragona, Tortosa, Barcelona, Mataró y Palamós. Cada capital de Departamento estaba gobernada por un Comandante principal que debía reunir la dirección y el gobierno de las matrículas de su extensión. Con este reparto podemos ver que Canarias quedaba fuera de esta Matrícula, ya que no pertenecía ninguno de esos tres departamentos.

Todo ese cuerpo militar estaba a su vez dividido en tercios navales dentro de cada Departamento, quedando comprendido en Tercios Navales de Levante, de Poniente y del Norte respectivamente. Los matriculados quedaban organizados en trozos, que eran unidades de 20 a 39 hombres formados por los artilleros y marineros de cada pueblo. Cada trozo recibía la denominación del pueblo al que pertenecía seguido de un número ordinal correlativo.

En lo que se refiere a la representación por regiones destaca Galicia, que llegó aportar casi un tercio de los matriculados ${ }^{15}$, y destaca también la gran envergadura de la flota catalana.

El principal privilegio consistía en la exención de las cargas concejiles de bagajes, depósitos, tutelas y mayordomías, pero, como han señalado López Mi-

13 Roberto FERNÁNDEZ DÍAZ y Carlos MARTÍNEZ SHAW, «La pesca en la España del siglo XVIII. Una aproximación cuantitativa (1758-1765)», Revista de Historia Económica, Año II, № 3 (pp 183-201), Madrid, otoño 1984, pp. 184-185.

14 Ángel O’DOGHERTY, «La Matrícula de Mar en el reinado de Carlos III», Anuario de Estudios Americanos, T. IX, Sevilla, 1952 , p. 357.

15 Ofelia REY CASTELAO, «Mutaciones sociales en una sociedad inmutable: el reino de Galicia en el reinado de Felipe V», en Eliseo SERRANO (ed.), Felipe V y su tiempo, Zaragoza, Diputación de Zaragoza, 2004, p. 357. 
guel y Mirabet Cucala más que un privilegio, se trataba de un ardid del que se valió la Corona para conseguir que la pretendida voluntariedad de la matrícula recayera en la totalidad de los que ejercían oficios marítimos ${ }^{16}$. Es decir, los gravámenes eran ostensiblemente superiores a las exenciones.

La Matrícula fue un sistema bastante impopular: los afectados no veían ventajoso el acuerdo, a pesar de que les respetaran el derecho exclusivo a pescar, que era algo que ya venían haciendo sin contrapartidas. La gente procuraba burlar sus imposiciones tratando de dedicarse a la pesca sin registrarse para liberarse de las obligaciones militares. Las huidas ante la llegada de los funcionarios encargados de realizar las listas de matriculados fue frecuente. Además, una vez requeridos a filas, las deserciones fueron abundantes. La imputación del delito de deserción constituía una amenaza importante para aquellos que incumpliesen las Ordenanzas, con sentencias severas que consistían en la realización de campañas o trabajos en los arsenales ${ }^{17}$.

Otra dificultad importante, a la hora de hacer un recuento, era valorar las categorías de cada marino, porque no se especificaban las actividades de cada uno. Además, si hacemos caso a las quejas de los funcionarios, habría que añadir un porcentaje de ocultaciones que debió de ser superior al $20 \%$ del total. También tuvo consecuencias en el incremento de la mortalidad debido a accidentes provocados por la entrada en combate.

En un Real Decreto de Carlos IV, del 8 de marzo de 1793, se reconocen las dificultades en la aplicación del sistema, sobre todo en Cádiz y Ferrol, reafirmando que los matriculados tienen el privilegio exclusivo de la pesca y navegación ${ }^{18}$.

Nueve años más tarde, la Ordenanza de 12 de agosto de 1802 otorgaba a la institución el carácter de cuerpo militar, lo que significa que la Matrícula pasa a ser el medio a través del cual se consigue tener permanentemente bajo control militar a los matriculados, incluso cuando estén fuera del servicio. Esto hace que el sistema adquiera mayor rigidez y jerarquización.

Con motivo de la guerra contra Inglaterra de 1805, Carlos IV libró una cédula por la que permitía que hombres que no fueran de tradición marinera pudiesen ser contratados en las compañías de pesca, porque todos los matriculados útiles estaban prestando servicio en dicha contienda y comenzaba a

16 Olga LÓPEZ MIGUEL y Magda MIRABET CUCALA, «La institucionalización...», op. cit., p. 231.

17 José Manuel VÁZQUEZ LIJO, Las Matrículas de Mar en la España..., op. cit. Igualmente aparece este dato en otras monografías sobre arsenales en España como María Teresa PÉREZ-CRESPO MUÑOZ, El arsenal de Cartagena en el siglo XVIII, Madrid, Naval, 1992. José Antonio SÁNCHEZ MARROQUÍ, Cartagena del Mediterráneo y su Arsenal Siglo XVIII. Evolución histórica a través del modelismo naval, Mallorca, Escuela Balear de Náutica, 2006. José QUINTERO GONZÁLEZ: La Carraca: el primer arsenal ilustrado español (1717-1776), Madrid, Ministerio de Defensa, Secretaría General Técnica, 2004.

18 Novísima Recopilación de las Leyes de España. Libro VI, Título VII, Ley I, 8 de marzo de 1793. Edición Facsímil, Madrid, Boletín Oficial del Estado, 1975, pp. 105-106. 
escasear el pescado para el abastecimiento público, además de suponer una merma para la Real Hacienda. Los nuevos empleados en dicha actividad gozarían de los mismos privilegios que los matriculados, pero habrían de ser registrados en otras listas para que, al cabo de dos años, o bien se alistasen en la Matrícula de Mar, o bien quedasen separados de ese trabajo y de sus consiguientes privilegios ${ }^{19}$.

El establecimiento de la Matrícula de Mar no entró en vigor en Indias al mismo tiempo que en España. En 1747 hubo un frustrado proyecto para implantarla en La Habana, pero finalmente, se llevó a cabo por medio de una Real Orden de 23 de agosto de 1776, con copia de José Gálvez secretario de Indias, dirigida a la gobernación de La Habana, a los virreyes de Perú y de Nueva España, y a los gobernadores de Santo Domingo, Yucatán, Puerto Rico, Filipinas, Caracas y Lui$\operatorname{sian}^{20}$. Los principios fundamentales de esta Matrícula en Indias eran los mismos que la Ordenanza de Ensenada. No existe ninguna constancia de registro de Matrícula alguno con anterioridad a 1777.

Las Matrículas en Indias estaban organizadas por funcionarios de acuerdo al siguiente esquema espacial: La Habana, Santiago de Cuba, Trinidad, Lima, Arica, Cartagena de Indias y Veracruz.

La reforma de la Matrícula de 1802 afectó también a América, y suponía un incentivo para proceder a un nuevo recuento de los efectivos marítimos españoles en Indias. Se realizaron nuevos recuentos en 1803, 1804 y 1811, pero ninguno de ellos detalla el número de individuos dedicados a las actividades pesqueras ${ }^{21}$.

El proceso de extinción de la Matrícula fue puesto en marcha por el primer gobierno liberal, por medio de un expediente de 1812 que para Indias fue definitivo, puesto que el restablecimiento durante la reacción absolutista, el 20 de febrero de 1817, no había tenido resultado práctico allí: la revocación definitiva se produjo el 28 de octubre de 1820, y se publicó un Nuevo Reglamento de Matrículas el 19 de enero de 1821, pero no pudo aplicarse en una América independiente ${ }^{22}$.

El decreto de 1820 fue derogado tres años más tarde y volvió a regir la Ordenanza de 1802 que se mantuvo, si bien con sucesivas modificaciones, hasta que

19 Novísima Recopilación de las Leyes de España. Libro VII, Título XXX, Ley XVIII, 31 de marzo de 1805. Edición Facsímil, Madrid, Boletín Oficial del Estado, 1975, p. 651.

20 Adelaida SAGARRA GAMAZO, «Una institución guipuzcoana, la Matrícula de Mar, implantada en y desde Cartagena de Indias, a través de los Fondos del Archivo General de Simancas", en Ronald ESCOBEDO MANSILLA, Ana DE ZABALLA BEASCOECHEA y Óscar ÁLVAREZ GILA, Comerciantes, mineros y nautas. Los vascos en la economía americana, Vitoria, Universidad del País Vasco, 1996, pp. 91117, específicamente p. 105.

21 Amparo MORENO GULLÓN, «La Matrícula de Mar en Campeche (1777-1811)», Espacio, Tiempo y Forma, Serie IV, Historia Moderna, T. 17, Madrid, 2004, pp. 284-286.

22 Marina ALFONSO MOLA y Carlos MARTÍNEZ SHAW, «La introducción de la Matrícula de Mar en Indias», en Carlos MARTÍNEZ SHAW y José María OLIVA MELGAR (eds.), El sistema atlántico español (siglos XVII-XIX), Madrid, Marcial Pons, 2005, p. 284. 
la Ley de Inscripción marítima de 26 de marzo de 1873 estableció un nuevo sistema de recluta militar.

\section{LA MATRÍCULA DEL MAR EN CANARIAS}

El sistema de Matrícula no fue trasplantado a Canarias de modo inmediato, ni siquiera al mismo tiempo que en las colonias americanas. No hemos hallado documentación que explicite las causas de ese retraso, que sin duda debía ser el goce de exenciones y privilegios que poseía el Archipiélago desde la colonización, refrendado en el siglo XVIII conla aprobación del Reglamento de $1718^{23}$.

El cabildo de Tenerife expone en 1770 de forma tímida que la gente de mar del Archipiélago no goza del fuero de marinería por no estar matriculados ${ }^{24}$. Sin embargo, no se pronuncia ni en uno ni en otro sentido: denota una cierta insatisfacción de no contar con esos privilegios, pero no se atreve a afirmar que la contrapartida podría resultar compensatoria.

En la Descripción de Canarias que hizo en 1776 José Varela y Ulloa, hace una defensa de la incorporación de las islas en el sistema de Matrícula mostrando los presuntos beneficios para ambas partes:

«Siendo el establecimiento de la Matrícula de gente de mar el único medio que se ha conocido para fomentar la marinería no hay duda de que en ninguna parte produciría esta sabia disposición mayores ventajas que en una Provincia compuesta Isleña cuya comunicación debería formar muchos marineros. Por desgracia los que siguen esta profesión en las Canarias no logran de las ventajas del Matriculado porque en estas siete Islas no hay matrícula que les aumente su marinería y consiguientemente las utilidades que les resultaría con dar esta ocupación a mayor número de sus naturales en cuyo particular interesa tanto la Marina Militar, y finalmente en una Provincia toda de Isleños no hay una escuela de Pilotaje por la cual se admiten a navegar a Pilotos muchos Extranjeros» ${ }^{25}$.

El tema de las pesquerías africanas y los canarios fue objeto de diversos debates en las Reales Sociedades Económicas de Amigos del País, así como en la legislación de la época ${ }^{26}$. De este modo, se debatieron entre los impulsos de los in-

${ }^{23}$ El texto del Reglamento está reproducido en María del Carmen GARCÍA BERNAL, «Los navíos de permisión tras el Reglamento de 1718: una valoración cuantitativa (1720-1730)», V Coloquios de Historia Canario-Americana, T. I: 747-792, Las Palmas de Gran Canaria, 1982, pp. 777-792.

24 A.M.L.L. Sig: P-XXX, Leg: 11, Año 1770, fol. 14 r.

25 A.M.N. Manuscrito 131, fol. 54 r-v.

26 José DE VIERA Y CLAVIJO, Extracto de las actas de la Real Sociedad Económica de Amigos del País de Las Palmas (1777-1790), Las Palmas de Gran Canaria, Real Sociedad Económica de Amigos del País de Las Palmas, 1981, pp. 108-113. Sobre legislación sirve de ejemplo la Real Orden dirigida al Regente de la Audiencia de Canarias, suprimiendo varios gravámenes sobre el pescado al objeto de favorecer el desarrollo de las pesquerías canario-africanas; en Antonio M. MACÍAS HERNÁNDEZ y María OJEDA CABRERA, Legislación ilustrada y sociedad isleña, Santa Cruz de Tenerife, Fundación InsidesCaja Canarias, 1988, p. 149 
novadores y las resistencias de lo que se ha denominado el antiguo régimen pesquero: actitudes conservacionistas, matrícula del mar, compañías privilegiadas, amortización de la almadraba, fiscalidad feudal, etc. Los primeros defendieron las posibilidades de la oferta pesquera ante una demanda que iba en aumento dado el incremento continuado de la población en la segunda mitad del siglo, especialmente en las ciudades, mientras que los últimos defendieron la preservación de los mares a través de una concepción conservacionista ${ }^{27}$.

Por otro lado, en 1786, junto con otras iniciativas para intensificar la pesca canaria, se trató específicamente el caso de las actividades que se desarrollaban en las pesquerías africanas, que la consideraban la «Escuela de la Marinería de estas Islas", ocupando a más de 4.000 hombres y abasteciendo de pescado salado a todo el Archipiélago. En este sentido, se estudió hacer una «Matrícula de gente de mar» como medio para fomentar la marinería en Canarias, argumentando que al ser ésta una realidad archipielágica, debía formar a muchos marineros, ya que detrás de eso estaba el interés del Estado en contribuir a la Marina militar. En cualquier caso, la ausencia de una escuela de aprendizaje hacía que fuera importante el número de pilotos extranjeros ${ }^{28}$. El Cabildo de Tenerife también trató de fomentar esta actividad:

«... el ejercicio de la Pesca en que se ocupan algunos pocos vecinos de esta Ciudad y de la de La Palma es muy recomendable, y exige que se le fomente en todo lo posible porque conocidamente va decayendo, y si acabare faltará el preciso abasto de las Islas de que se surten Ricos y Pobres como es notorio... ${ }^{29}$.

El número de bergantines canarios ascendía a 28 en 1803, con pesos variables entre 15 y 35 toneladas, tripulados por más de 800 pescadores, de los que 22 tenían su origen en Gran Canaria, 4 en La Palma, 1 en Lanzarote y 1 en La Gomera $^{30}$. Destaca la aparición de un barco gomero, que resulta novedoso frente a lo que ocurría en el siglo XVIII.

Sin embargo, tendremos que esperar a 1804 para que la Matrícula de Mar fuese aplicada a Canarias, que además aparecerá vinculada a la de Indias. El 6 de julio de 1804 se estableció en Tenerife una Subdelegación de Matrícula, por cuya

27 Roberto FERNÁNDEZ DÍAZ y Carlos MARTÍNEZ SHAW, «Las revistas de inspección de la Matrícula de Mar en el siglo XVIII», en Carlos MARTÍNEZ SHAW (Ed.), El derecho y..., op. cit., p. 242.

28 A.M.N. Manuscrito 1.955, s/fol. La realidad isleña había quedado fuera de la Matrícula del mar en un primer momento, con lo que no obtenían las ventajas del matriculado. Este tema está tratado de forma precisa en Roberto FERNÁNDEZ DÍAZ y Carlos MARTíNEZ SHAW, «Las revistas de...», op. cit., p. 242. En cuanto al tema de los pilotos especializados, comienzan a aparecer desde el siglo XVII. Conocemos el caso de Santander, donde regularon como práctica habitual del puerto el pilotaje, que realizaban en pequeñas embarcaciones de la Villa, sobre todo, a raíz de las concordias con comerciantes extranjeros y, en la década de los veinte del siglo XVII, se estableció el nombramiento de un piloto mayor. María José ECHEVARRÍA ALONSO, La actividad comercial del puerto de Santander en el siglo XVII, Santander, Autoridad Portuaria de Santander, 1995, p. 150.

29 A.M.L.L. Sig: P-XXX, Leg: 15, Año: 1769, fol. 83 recto.

30 A.G.M.A.B. Matrícula. Asuntos Particulares. Leg. 1.984, 29 de marzo de 1803, s/fol. 
disposición se registró a toda la gente de mar, «que no lo había estado desde la conquista», con lo que quedaban exentos de la jurisdicción ordinaria para quedar sujetos a la militar de la Real Armada ${ }^{31}$.

Haciendo balance, vemos que en 1812 doscientos hombres de la Matrícula de Canarias fueron enviados a Montevideo a combatir contra la insurrección de las provincias del Río de la Plata. Años más tarde, en 1823 se levaron también otros 70 hombres de las islas en el navío San Pablo y algunos más en diversos navíos de guerra española que hicieron escalas en el Archipiélago.

A pesar de esto, debemos señalar que en sentido estricto, la Matrícula nunca llegó a funcionar de forma adecuada en Canarias. El 14 de febrero 1815 encontramos quejas y peticiones para que se restableciera la Matrícula de Mar en el Archipiélago, igual que ocurriría dos años después, el 3 de octubre de 1817, prueba de que no había surtido efecto ${ }^{32}$.

Unos años después, la Real Orden de 18 de noviembre de 1825 mandó que pasaran a Cádiz 300 matriculados de Canarias, lo que generó problemas porque muchos de ellos estaban prestando servicio en los ejércitos de tierra de milicias. Pero los matriculados querían quedar exentos de los regimientos terrestres, tal como estaba recogido en las ordenanzas; sin embargo, los comandante generales de Canarias no los dejaron que volviesen a la Matrícula.

El Comandante Militar de Marina de Canarias informó el 4 de enero de 1826 al Director General de la Armada de que el Comandante General de Canarias pretendía obtener permiso para que los milicianos provinciales de Santa Cruz de Tenerife pudiesen dedicarse a la pesca. Desde el poder central se le replicó que si todos los comandantes generales de las islas hubiesen cumplido las órdenes con exactitud, no se hubiese formado el cuerpo de milicias (constituido por 12 regimientos de 400 hombres) con pescadores, sino que a éstos se les hubiese registrado en la Matrícula de Mar. Lo único aprobado fue la libertad de pescar con cañas desde los muelles y marisquear en las playas, pero sin barcos, cosa que, evidentemente, podían hacer con anterioridad.

Además, argumenta, en contra de la pretensión de que la marinería se hallaba preparada para el servicio de marina en cuanto hubiese fondos y, para eso, recordaba que los matriculados canarios habían participación en buques de guerra, de transportes y de pesca en Montevideo y en La Habana.

El Director General ratificó, junto con el Comandante General del Departamento de Cádiz y el principal de aquellos tercios navales, que resultaba útil man-

31 Isidoro Romero y Ceballos: Diario cronológico histórico de los sucesos elementales, políticos e históricos de esta isla de Gran Canaria (1780-1814), T. II, Las Palmas de Gran Canaria, Cabildo Insular de Gran Canaria, 2002, p. 99.

32 A.G.M.A.B. Matrículas. Generalidades. Leg. 1.899, s/fol. Y Comandancias Militares. Leg. 5.519, s/fol. 
tener y mejorar la Matrícula en aquellas islas. En esos momentos, 1826, en Canarias había 2.102 hombres anotados como útiles para el servicio de marina. En estos expedientes contabilizan 30 bergantines que faenan en el Banco Sahariano, además de los 300 hombres que se encuentran en La Habana al servicio de seis buques de guerra ${ }^{33}$.

En una carta de 28 de mayo de 1830, el comisionado regio de Canarias expone al Comandante de Mar de la Provincia de Canarias los datos que se le habían encargado acerca de la Revista de Inspección establecida por la Real Orden de 3 de diciembre de 1825. La Real Junta Superior del Gobierno de la Armada, tras examinar los documentos de dicha Revista, manifestó que se reducían a las listas nominales de individuos matriculados, por eso le criticaron la falta de referencias a la forma de mejorarla, tal como exigía la ordenanza.

El artículo 124 de la Ordenanza disponía que se observara la Matrícula en Indias y en Canarias, lo que permitía a los mareantes dedicarse a actividades del mar. Este hecho generó un problema, porque muchos de ellos se negaban a contribuir al fondo económico de los gremios, y, en consecuencia, estas instituciones, que estaban presentes en todos los puertos principales de las islas, litigaron por mantener esos cobros.

A pesar de todas estas disposiciones encaminadas a restablecer la legalidad en cuanto a la Matrícula canaria, el Comandante General quiso seguir contando con los matriculados para el reemplazo del regimiento de milicias de infantería que tenía más de 1.200 hombres $^{34}$.

Al final del Antiguo Régimen, el Capitán General de Cádiz recibe comunicación del Comandante de Mar de Canarias acerca de la lamentable situación en que se encuentra la Matrícula en esas islas. Apoyándose en una Real Orden del 8 de febrero de 1827, solicita que los matriculados que en ese momento no estén empleados en la navegación o en la pesca puedan obtener carta de seguridad, licencia de caza, pasaporte y otros documentos para que mantengan sus fuero, Esto viene motivado por el hecho de que cuando son despedidos del servicio, tras haber cumplido su campaña, los matriculados no llevan recompensa alguna a sus hogares, más que el derecho de pescar.

La provincia de Canarias estaba dividida en nueve distritos marítimos, de los que tres correspondían a Tenerife, ubicados en la costa norte, y los otros seis eran cada una de las islas. Los individuos matriculados con fecha 10 de julio de 1830 eran los siguientes:

33 A.G.M.A.B. Matrículas. Generalidades, Leg. 2.029, 1826, s/fol.

34 A.G.M.A.B. Matrículas. Asuntos Particulares, Leg. 2.034, s/fol. 


\begin{tabular}{|l|c|}
\hline Santa Cruz de Tenerife & 386 \\
\hline La Orotava & 324 \\
\hline Garachico & 182 \\
\hline Gran Canaria & 1.461 \\
\hline La Palma & 438 \\
\hline Lanzarote & 664 \\
\hline Fuerteventura & 79 \\
\hline La Gomera & 80 \\
\hline El Hierro & 11 \\
\hline Total & 3.625 \\
\hline
\end{tabular}

FUENTE: A.G.M.A.B. Matrículas. Leg. 2.034. Elaboración propia

Tenerife, a pesar de contar con tres distritos diferentes, suma 892 hombres, mientras que Gran Canaria supera esta cifra en 569 matriculados, lo que se explica por el claro predominio de esta isla en las labores pesqueras, especialmente en el Banco Sahariano. También podemos destacar que Lanzarote está cerca de Tenerife en número de pescadores y ha superado claramente a La Palma, cosa que no ocurría durante los siglos XVI, XVII y XVIII. Por su parte, Fuerteventura es inferior a La Gomera, y la cifra de El Hierro es prácticamente insignificante. Todos estos datos vuelven a plasmar la realidad pesquera del Archipiélago condicionada por un conjunto de factores físicos y sociales que explican el por qué unas islas estuvieron más vinculadas a la pesca en el Banco Sahariano que otras y aquí ya está expuesta la realidad pesquera canaria que se mantendrá constante en los siglos XIX y XX.

Según otro recuento que hemos hallado, relacionado con la Matrícula de Mar, en 1830 había 132 buques, de los cuales 5 estaban destinados al tráfico mercantil con América, sólo uno comerciaba con Europa, 83 eran pequeñas embarcaciones que comunicaban las islas entre sí y 33 eran destinados a la pesca en el Banco Sahariano. Evidentemente, estos datos no incluyen las lanchas de auxilio, cargas y descargas, ni los botes que faenaban entre los muelles insulares y se dedicaban a la captura del «pescado fresco».

Los 33 barcos destinados a la pesca sahariana eran 10 bergantines y 7 bergantines-goletas de Tenerife; 8 bergantines-goletas y 2 bergantines de Gran Canaria; y 3 bergantines-goletas, 1 goleta, 1 paquebote y 1 barco de pozo y vela redonda de La Palma. Los bergantines tenían un tonelaje que iba de 49 a 30.5, los bergantines-goletas entre 54 y 16 , el paquebote pesaba 27,5 toneladas, el barco de pozo y vela era de 5 y la goleta de 18 toneladas ${ }^{35}$.

${ }^{35}$ A.G.M.A.B. Matrículas. Asuntos Particulares. Leg. 2.034, 8 de julio de 1830, 3 fols. 
A continuación mostramos los buques dedicados a la pesca en el Banco Sahariano por islas:

\begin{tabular}{|l|l|c|}
\hline \multicolumn{1}{|c|}{ TENERIFE } & \multicolumn{1}{c|}{ Nombre $^{36}$} & Toneladas \\
\hline Bergantín & Soledad & 49 \\
\hline Bergantín & San Nicolás & 42 \\
\hline Bergantín & San Amaro & 46 \\
\hline Bergantín & Venus & 36 \\
\hline Bergantín & San Francisco Javier & 38 \\
\hline Bergantín & La Soledad & 42 \\
\hline Bergantín & San Fernando & 49 \\
\hline Bergantín & San Luís & 30,5 \\
\hline Bergantín & Buen Viaje & 48,5 \\
\hline Bergantín & Gran Poder de Dios & 38 \\
\hline Bergantín-Goleta & San Miguel & 45,5 \\
\hline Bergantín-Goleta & San Rafael-Brillante & 29,5 \\
\hline Bergantín Goleta & San José & 39,5 \\
\hline Bergantín-Goleta & San Antonio & 40 \\
\hline Bergantín-Goleta & La Ninfa & 39 \\
\hline Bergantín-Goleta & La Aurora-Cibeles & 21,5 \\
\hline Bergantín-Goleta & Ntra. Sra. Del Rosario & 29 \\
\hline
\end{tabular}

\begin{tabular}{|l|l|c|}
\hline \multicolumn{1}{|c|}{ GRAN CANARIA } & \multicolumn{1}{c|}{ Nombre } & Toneladas \\
\hline Bergantín & Ntra. Sra. Del Rosario & 22 \\
\hline Bergantín & Gran Poder de Dios & 38 \\
\hline Bergantín-Goleta & Jesús María & 28,5 \\
\hline Bergantín-Goleta & San Sebastián & 24 \\
\hline Bergantín-Goleta & Jesús, María y José & 25 \\
\hline Bergantín-Goleta & José-Doble Rosa & 46 \\
\hline Bergantín-Goleta & José-Africano & 35 \\
\hline Bergantín-Goleta & Ntra. Sra. de los Dolores-Perla & 50 \\
\hline Bergantín-Goleta & Ntra. Sra. del Rosario-Fe & 60 \\
\hline Bergantín-Goleta & San José-Diamante & 58 \\
\hline
\end{tabular}

36 En cuanto a los nombres, predominan de santos y vírgenes, pero aparecen ocho nombres no religiosos, y en ocasiones, le ponen dos nombres, normalmente uno religioso y otro no. 


\begin{tabular}{|l|l|c|}
\hline LA PALMA & Nombre & Toneladas \\
\hline Bergantín-Goleta & San Patricio & 16 \\
\hline Bergantín-Goleta & San Benedicto & 54 \\
\hline Bergantín-Goleta & Gran Poder de Dios & 25 \\
\hline Goleta & Margarita & 18 \\
\hline Paquebote & Adelaida & 27,5 \\
\hline Barco Vela Redonda & Santa Ana & 5 \\
\hline
\end{tabular}

FUENTE: A.G.M.A.B. Matrículas. Asuntos Particulares. Leg. 2.034. Elaboración propia.

Según los datos del total de toneladas que aporta esta fuente, Tenerife tenía 663, Gran Canaria 386,5 y La Palma 145,5, es decir que, según este informe sería Tenerife (por estar más poblada y demandar más pescado) la isla que habría tenido más presencia en todos los sentidos en el Banco Sahariano. Este extremo nos resulta inverosímil ya que contrasta con otros datos que hemos podido ir averiguando: sabemos por otras fuentes que en todo momento fue mayor el predominio de Gran Canaria, y que incluso en estas fechas, el número de habitantes de esta isla que se hallaban matriculados era considerablemente superior a los tinerfeños. Estos datos habían sido aportados desde Tenerife, la isla donde estaba el poder político-militar en ese momento, es posible que por ello no contaran con los datos completos de Gran Canaria, que creemos que debían ser más elevados.

Además, los informes indican que los canarios hacen continuos reemplazos en los buques de la Armada en La Habana y en Puerto Rico; de hecho, afirman que en ese año, 1833, debía de haber entre 100 y 150 matriculados canarios cumpliendo en estos destinos. Por todos estos perjuicios, las autoridades juzgan que la Matrícula del Mar en Canarias estaba en franca decadencia ${ }^{37}$.

En resumen, la Matrícula de Mar con los antecedentes del siglo XVII, el primer decreto de empadronamiento en 1717, hasta la plena militarización en 1802, y la incorporación de Canarias en 1804, fue un referente indispensable a tener en cuenta en el mundo de la pesca española hasta 1873, en que desaparece este sistema de reclutamiento. Durante los reinados borbónicos del antiguo régimen, la marinería experimentó un incremento sustancial, la Real Armada fue rehecha y pudo superar el declive en el que estaba sumida. Sin embargo, no parece haber obtenido los resultados esperados por la Monarquía y, podemos considerar que, para el sector pesquero, el balance fue negativo.

37 A.G.M.A.B. Matrículas. Generalidades, Leg. 1.913, 30 de julio de 1833, s/fol.U 